\title{
MORE NOTES ON THE MARINE MOLLUSCA OF NEW SOUTH WALES.
}

\author{
By \\ Tom Iredale, \\ Conchologist, Australian Museum, Sydney. \\ (Plates lxii-lxv.)
}

The marine molluscan fauna of New South Wales was catalogued by Hedley ten years ago; since then collecting has been carried on intensively and the distribution of many species determined. Mr. A. W. O'Sullivan made collections at the Richmond River and these indicated that a rich fauna with a sprinkling of northern forms exists there and that many records will be added from that area. This is confirmed by collections made at Caloundra, Queensland, by Whitley, Mort and myself, where many northern forms were commonly found and most of which probably occur in northern New South Wales. The late Mr. G. MacAndrew searched at Shellharbour, and Master Consett Davies at Bulli, while $\mathrm{Mr}$. A. J. Thackway has made collections at many places along the coast, notably at Port Stephens, regarding which a separate account may be published.

The beaches around Sydney from Palm Beach in the north to Cronulla in the south have been continually searched by Whitley, Mort, Davies, and myself, and many species regarded as rare have been found to be of common occurrence. With other officers of the Museum staff, Messrs. McNeill, Livingstone, Whitley, Boardman, and Fletcher, I investigated the marine fauna of Gunnamatta Bay, Port Hacking, and obtained a large series of soft-bodied mollusca, which it is proposed to deal with separately.

In the determination of many species it has been found necessary to discuss the range of the species throughout southern Australia and a list is being prepared embodying the results of the investigations.

Pronucula mayi $s p$. nov.

An excellent figure of a Pronucula, identified as $P$. decorosa by May, ${ }^{1}$ shows many differences, as May himself pointed out, so I propose to name the species $P$. mayi, the type locality being Pilot Bay, South Tasmania.

\section{Cucullata concamera (Bruguière).}

An older name for the typical species of Cuculloca is labiata Solander, ${ }^{2}$ but the New South Wales form so-called can be separated

${ }^{1}$ May.-Proc. Roy. Soc. Tasm., 1915, p. 81, pl. viii, f. 42.

2 Solander-Catalogue of the Portland Museum, 1786, p. 185. 